\title{
El pesimismo antropológico en Hobbes desde una visión poliana
}

\author{
Zhenia Djanira Aparicio Aldana \\ Universidad de Piura
}

Thomas Hobbes fue un filósofo moderno cuyo pensamiento abarca temas muy diversos, como la antropología, la política, la ciencia del Estado y de la sociedad. Al ser un pensador del siglo XVII, su filosofía se encamina de manera especial a justificar la existencia del Estado bajo un sistema absolutista. Para Hobbes, el Estado se presenta como una persona artificial que proporciona seguridad y paz a un hombre envuelto en un estado de naturaleza de odio y guerra. La frase homo homini lupus ejemplifica el pesimismo antropológico del hombre moderno, que actualmente se refleja en un reduccionismo, característico de la crisis de la cultura contemporánea, propuesta por Leonardo Polo.

\section{La justificación del Estado}

En Occidente las grandes formas históricas políticas fueron usualmente la polis griega, la urbs romana, la civitas cristiana y la nación. El Estado evolucionó adoptando variadas formas o subformas a medida que concentraba más poder, y se convirtió en una necesidad para la sociedad. Esta exigencia social es plasmada en Hobbes en su Leviathan, como una inclinación al poder:

El mayor de los poderes humanos es el que se integra con los poderes de varios hombres unidos por el consentimiento en una persona natural o civil; tal es el poder de un Estado, o el de un gran número de personas, cuyo ejercicio depende de las voluntades de las distintas personas particulares [...] Por consiguiente, tener siervos es poder; tener amigos es poder, porque son fuerzas unidas. También la riqueza, unida con la libertad, es poder, porque procura amigos y siervos. ${ }^{1}$

Con la finalidad de justificar el Estado, Hobbes considera que el hombre está por naturaleza en estado de guerra permanente con los demás, razón por la que se origina el miedo en él. La fuerza es la ley de la humanidad y vivir está

Thomas Hоввеs, Del ciudadano y Leviathan. Madrid, Tecnos, 2013, p. 146. 
en habitar un estado de guerra. Afirma que los hombres pactan un contrato renunciando a sus respectivos poderes y trasladando a un tercero, que es el Estado, el poder soberano. Se pasa así, del estado de naturaleza, o reino de la necesidad y de la guerra, al estado civil o político donde las leyes establecidas son siempre justas, con lo que se logra la seguridad buscada.

Para Hobbes la sociedad civil es un hombre o persona artificial que quiere y actúa por todos, y cada uno de sus miembros. Este artificio, calculado y construido con la precisión de una máquina perfecta, es el Leviathan, nombre de un monstruo bíblico que simboliza el 'Dios mortal' que asegura la paz. Hobbes a partir de su teoría busca justificar el poder hegemónico o supremo en una comunidad:

La naturaleza (el arte con que Dios ha hecho y gobierna el mundo) está limitada de tal modo, como en otras muchas cosas, por el arte del hombre que éste puede crear un animal artificial [...] En efecto: gracias al arte se crea ese gran Leviathan que llamamos república o Estado (en latín, civitas) que no es sino un hombre artificial, aunque de mayor estatura y robustez que el natural, para cuya protección y defensa fue instituido, y en el cual la soberanía es un alma artificial que da vida y movimiento al cuerpo entero; los magistrados y otros funcionarios de la judicatura y del poder ejecutivo. ${ }^{2}$

Así, para el nacimiento del Estado en Hobbes es conveniente realizar un pacto que el individuo accede llevado por su egoísmo, lo cual permitirá el tránsito de un estado de naturaleza a un estado social o civil. Los derechos se ceden a un Estado que maneja la libertad del hombre y, por ende, lo controla y lo autodetermina.

\section{El pesimismo en el hombre y la necesidad del Estado}

El pesimismo antropológico no es otra cosa que el pesimismo intelectual en el hombre. Si queremos darle un origen, este se encuentra en el siglo XIV en dos personajes: Duns Escoto y Guillermo de Ockham, quienes, con el propósito de salvar la fe ante el "racionalismo de Aristóteles", afirmaron que el hombre no es intelectualmente capax Dei. ${ }^{3}$ La carga pesimista continúa y llega a Hobbes. En este sentido, Leonardo Polo sostiene: “Hobbes entendió muy bien la significación antropológica del nominalismo. Su famosa tesis: homo homini lupus es simple glosa del voluntarismo de Ockham en el nivel humano". ${ }^{4}$

Los difusores del pesimismo antropológico que envuelve hoy la sociedad contemporánea renuncian a la optimización de adherirse al bien de manera

Thomas Новвеs, Del ciudadano y Leviathan..., p. 65.

Alberto VArgas, Genealogía del miedo. Un estudio antropológico de la modernidad desde Leonardo Polo. Pamplona, Universidad de Navarra, 2017, p. 65.

4 Leonardo Polo, Presente y futuro del hombre. Madrid, Rialp, 2012, p. 55.

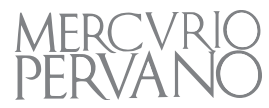


trascendental, y ponen en peligro la armónica concepción clásica de los trascendentales: verdad y bien. Así, "[1]a doble vida tan característica de nuestra sociedad es la consecuencia de la desvinculación íntima del hombre con Dios; es la manifestación de la desorientación personal de cada hombre". ${ }^{5}$ Las formas de pensar, basadas en un pesimismo antropológico, llevan al hombre a su destrucción, pues no es comprensible la realización del hombre al margen de su trascendencia hacia Dios y hacia los otros hombres.

La concepción pesimista del hombre en Hobbes se refleja en la naturaleza egoísta del ser humano. Por egoísmo Hobbes entiende la tendencia natural del hombre a la autoconservación. El egoísmo en estado puro se encuentra en el estado de naturaleza y, por ende, el mismo excede y está por fuera de todo criterio racional o valorativo. Para esto el filósofo parte de la igualdad entre todos los hombres, y afirma que todos aspiran a lo mismo, y si esto no es logrado llegan la enemistad y el odio. Hobbes parte de que los seres humanos son más bien iguales que desiguales:

No hay, en efecto y de ordinario, un signo más claro de distribución igual de una cosa, que el hecho de que cada hombre esté satisfecho con la porción que le corresponde. De esta igualdad en cuanto a la capacidad se deriva la igualdad de esperanza respecto a la consecución de nuestros fines. Esta es la causa de que si dos hombres desean la misma cosa, y en modo alguno pueden disfrutarla ambos, se vuelven enemigos, y en el camino que conduce al fin (que es, principalmente, su propia conservación y a veces su delectación tan solo), tratan de aniquilarse o sojuzgarse uno a otro" ${ }^{\prime 6}$.

En la filosofía de Hobbes, la existencia de un estado de naturaleza o presocial no es nada positivo. Menciones en el Leviathan como "Así hallamos en la naturaleza del hombre tres causas principales de discordia: primera, la competencia; segunda, la desconfianza; tercera, la gloria. La primera causa impulsa a los hombres a atacarse para lograr un beneficio; la segunda, para lograr seguridad; la tercera, para ganar reputación..." o "[e]n esta guerra de todos contra todos se da una consecuencia: que nada puede ser injusto. Las nociones de derecho e ilegalidad, justicia e injusticia están fuera de lugar. Donde no hay poder común, la ley no existe: donde no hay ley, no hay justicia. En la guerra, la fuerza y el fraude son las dos virtudes cardinales...", 7 nos indican que el hombre necesita una salida del estado de la naturaleza en que se encuentra. Para el filósofo, esta salida está en el estado civil. En este sentido, llegar para Hobbes a este estado social es permitir en el hombre el progreso.

Para el anhelado progreso y la obtención de una vida confortable, Hobbes propone el Leviathan, el cual ayudará al hombre a salir del estado de naturaleza,

Alberto VARGAs, Genealogía del miedo..., p. 68.

Thomas Hobbes, Del ciudadano y Leviathan..., p. 165.

Thomas Hоввеs, Del ciudadano y Leviathan..., p. 169.

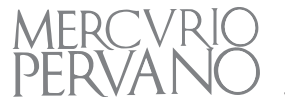


donde impera el egoísmo, y movido por un instrumento interno que es su autoconservación, llegará a constituir un estado social o civil que nos permite entender su pesimismo antropológico. En este pesimismo, el hombre se inclina desde sus pasiones a obtener una supuesta paz. Estas pasiones se concentran en el "temor a la muerte" y la paz, al "...deseo de las cosas que son necesarias para una vida confortable y la esperanza de obtenerlas por medio del trabajo..." Vemos que en Hobbes se centra, entonces, un egoísmo individual y difunde una filosofía utilitarista, soporte hoy del sentimentalmente existente.

Así, para comprender el pesimismo en Hobbes, es necesario distinguir dos estados para el hombre: el estado de naturaleza y el estado social. Por el primero, el hombre se siente envuelto en un estado de guerra capaz de sucumbir por otro ser, en el que vive salvajemente. En este estado, el hombre es juez de sí mismo dependiendo su seguridad de su propia fuerza para sostener su ley: el homo homini lupus de Hobbes se evidencia. El pensador inglés rompe con la teoría aristotélica: los hombres no tienen appetitus societatis en el estado de naturaleza, sino que se mueven por el deseo de autoconservación asocial que los perjudica. Nos dice en Leviathan: "El derecho de naturaleza, lo que los escritores llaman comúnmente ius naturale, es la libertad que cada hombre tiene de usar su propio poder como quiera, para la conservación de su propia naturaleza, es decir, de su propia vida..."

En este sentido, el pesimismo en Hobbes se centra en la existencia del miedo, el cual, combinado con el dictado de la razón, y de la inseguridad de la "guerra de todos contra todos", hace surgir el Estado o Leviathan como único capaz de llevar al hombre a la paz deseada. La existencia de este Estado hace centrar exclusivamente la existencia humana en la existencia política; y esto porque el mismo se caracterizaría como uno inmensamente fuerte, para poder dominar a la bestia que el hombre lleva en sí. Hobbes logra revestir a este Estado de todas las obligaciones y limitaciones contractuales, le otorga una autoridad casi ilimitada, y eleva al Leviathan a la categoría de "dios mortal". 10

Al ser el Leviathan una necesidad en el hombre, el pacto o contrato se configura como el medio para alcanzar el estado social. El traspaso de un estado de naturaleza a uno social se resume en el principio exeundum ese: sal del estado naturaleza y entra en un estado jurídico mediante la unión de voluntades, que consiste en una mutua transferencia de derechos al Leviathan. La consecuencia del razonamiento de Hobbes radica en que para frenar el estado de guerra de todos contra todos, y p a r dar paz al homo homini lupus es necesario constituir un estado civil que garantice eliminar la guerra, en la que la voluntad de confrontación violenta es abiertamente declarada.

\footnotetext{
Thomas Hobbes, Del ciudadano y Leviathan..., p. 170.

Thomas Hobbes, Del ciudadano y Leviathan..., p. 171.

10 Friedich Meinecke, La idea de la razón de Estado en la Edad Moderna. Madrid, Centro de Estudios Políticos y Constitucionales, 1997, p. 215.
} 
Nuevamente el pesimismo antropológico de Hobbes aparece en el estado social, el pacto o contrato celebrado por los hombres es débil, inseguro y trágico; y esto obedece a que es una regla para el hombre cumplir con los pactos que han celebrado. Sin ello, dice Hobbes "...los pactos son vanos, y no contienen sino palabras vacías, y subsistiendo el derecho de todos los hombres a todas las cosas, seguimos hallándonos en situación de guerra". ${ }^{11}$ El Estado social, propuesto por Hobbes, vive en riesgo y en tensión constante de que el pacto sea roto. Por esta razón, Leonardo Polo denomina a Hobbes como hipersensible, pues vive aterrado ante lo más vulnerante, de ahí que "lo específico del hombre sea la previsión de la amenaza". ${ }^{12}$

El hombre en el estado social se encuentra en ausencia de garantías. No hay duda de que la "visión apocalíptica" del pensador permite la posibilidad de la "regresión al estado de naturaleza", y esto porque los bienes individuales se verán en peligro ante el sobrecargo de habitantes. Esta situación tiene su término en la guerra, la cual se constituye como el último remedio del hombre, con lo que vuelve al pesimismo antropológico de Hobbes en cuanto a la congruencia de las necesidades con los recursos y las potencias del Estado. Por tanto, el estado civil provee una quimera de paz, de posesión y conservación, sometido al estado de guerra, y al imperio de la voluntad. El individuo obtiene su protección solo a través de la fortaleza del soberano, que, liberado de sus ataduras, debe desplegar su poder para sosegar los intereses particulares.

\section{Hobbes: reduccionismo y pesimismo}

Actualmente el hombre se encuentra en una tensión constante, en crisis. Ello no puede ser visto como una situación pasajera: la crisis es permanente. El crecimiento en el hombre lo puede llevar a un perfeccionamiento o desperfeccionamiento. Cuando el hombre decrece, se dice que se encuentra en crisis. La libertad se configura como un elemento inmanente al crecimiento del hombre, lo que determina su grado de perfección o su debacle. En vista de que su crecimiento puede detenerse o no encontrar los suficientes caminos o guías que lo lleven a la perfección, el hombre está expuesto a hallarse fatalmente en una situación de crisis. ${ }^{13}$ Tan igual aplicamos este pensamiento a la sociedad; por consiguiente, solo si admitimos que la sociedad es libre, podemos hablar de sociedad en crisis. La crisis de la cultura occidental manifiesta una crisis del hombre. Este es el modo como Leonardo Polo entiende la sociedad y su crisis contemporánea, a la que muchos llaman con razón la "crisis de la modernidad". ${ }^{4}$

Thomas Hoвbes, Del ciudadano y Leviathan..., p. 189.

Leonardo Polo, Presente y futuro del hombre..., p. 56.

Alberto VARgAs, Genealogía del miedo..., pp. 13-14.

4 Alberto Vargas, Genealogía del miedo, estudio desde L. Polo..., pp. 23-68.

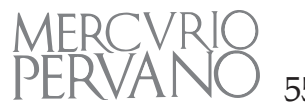


La crisis de la modernidad conlleva a una de naturaleza individual y otra social; la primera de índole subjetiva y la segunda objetivamente envolvente. Ambas conforman una "crisis antropológica", 15 que Leonardo Polo estudia, a la cual se le imputa la generación de una conciencia de crisis. Así, Polo nos dice escuetamente que una crisis "significa que ciertas convicciones pasadas han perdido su firmeza y no han sido renovadas". Y esto es común en nuestros tiempos:

En nuestra época aparece una conciencia de crisis, cuyas manifestaciones principales son: la crisis de la idea del cosmos, surgida en el plano científico; la crisis de la imagen universal del hombre, motivada por razones históricas; la crisis de la idea de que el hombre tiene un poder que se ejerce en el orden cultural, basada en la situación actual de la técnica; la crisis de la hegemonía del espíritu, por razones de varios tipos (...) Finalmente, está en crisis la dimensión religiosa del hombre. ${ }^{16}$

Pero ¿cómo se ha llegado a esta crisis? Es imprescindible partir de la modernidad, de su historia filosófica para encontrarnos con su propia crisis, donde se encuentran el miedo y la desesperanza como principal manifestación que lleva al hombre a la soledad. La crisis antropológica es íntima y personal; el hombre se encuentra escindido y fragmentado.

Esta crisis planteada por el filósofo español Leonardo Polo tiene aspectos que han venido dándose a partir de una situación histórica, entre los cuales podemos destacar los reduccionismos. El pensamiento de Hobbes se decanta en un reduccionismo, lo cual sustenta su pesimismo antropológico. Así, estos reduccionismos hacen referencia al enfoque en que se estudia al hombre. Para esto este intento de estudio recae en "averiguar la fuerza albergada en el hombre; uno quiere saber respecto de sí mismo con miras al resultado, a lo asequible, a lo factible ${ }^{\prime 17}$. Siguiendo esto, el cuestionamiento sobre el sentido de la vida en el hombre nos ha inclinado a preguntarnos sobre el impulso, la dotación tendencial que lleva al hombre a hacer algo. Esta reflexión no es negativa, la filosofía siempre se ha planteado la cuestión del sentido. El problema surge cuando la respuesta al intento de descubrir cuál es esa fuerza vital se centra

15 La noción de 'crisis antropológica' es acuñada por Alberto Vargas en su estudio sobre la genealogía del miedo. Ese estudio está basado en la filosofía de Leonardo Polo sobre la crisis de la cultura contemporánea. Vargas considera que esta crisis antropológica tiene las siguientes características: a) es desesperante, pues no se sabe cuándo se va a salir de ello o si se podrá salir; b) es compleja, es decir, compuesta de múltiples dimensiones, global y colectiva; c) es íntima, pues se ha interiorizado hasta el grado de pretender identificarse con ella; d) es fragmentaria, pues rompe la vida íntima social, social y con el cosmos; e) es esclavizante, ya que convive con una sensación falsa de libertad, pues identifica 'situación' con libertad. Cf. Alberto VArgas, Genealogía del miedo, estudio desde L. Polo..., p. 30.

16 Leonardo Polo, Presente y futuro del hombre..., p. 124.

17 Leonardo Polo, Presente y futuro del hombre..., p. 98.

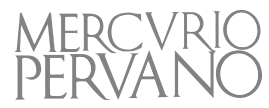


en un solo aspecto, o, como dice Polo, "en tan solo una veta de esa fuerza"; es en este momento que se incurre en reduccionismo. Hobbes es reduccionista, y esto a raíz de que "la fuerza que encauza realmente al hombre es el poder, no aureolado de gloria, sino el poder puro". ${ }^{18}$ Este postulado es evidente en el Leviathan, cuando Hobbes señala:

Así parece bien claro a mi entendimiento, lo mismo por la razón que por la Escritura, que el poder soberano, ya radique en un hombre, como en la monarquía, o en una asamblea de hombres, como en los gobiernos populares y aristocráticos, es tan grande como los hombres son capaces de hacerlo. Y aunque, respecto a tan ilimitado poder, los hombres pueden imaginar muchas desfavorables consecuencias, las consecuencias de la falta de él, que es la guerra perpetua de cada hombre contra su vecino, son mucho peores. La condición del hombre en esta vida nunca estará desprovista de inconvenientes; ahora bien, en ningún gobierno existe ningún otro inconveniente de monta sino el que procede de la desobediencia de los súbditos, y del quebrantamiento de aquellos pactos sobre los cuales descansa la esencia del Estado. Y cuando alguien, pensando que el poder soberano es demasiado grande, trate de hacerlo menor, debe sujetarse él mismo al poder que pueda limitarlo, es decir, a un poder mayor. ${ }^{19}$

La fuerza vital del hombre para Hobbes se encuentra en buscar ganar, prevalecer y alcanzar el dominio de los otros, y esta es su fuerza vital, guiado por la autoconservación. No olvidemos que Nietzsche iba por el mismo camino, quien contribuyó a crear un mundo sin Dios y a su vez afirmaba una individualidad poderosa. La mencionada autoconservación de Hobbes nos lleva a un reduccionismo, en el sentido de que todo se apuesta al dicho instinto que iguala al hombre y a los animales, lo cual es continuado en el siglo pasado por Darwin, quien "fundó su especulación acerca del proceso de la vida en ese instinto". ${ }^{20}$

Pensar en los reduccionismos, tal es el caso de Hobbes, que centra la fuerza vital del hombre en el instinto o en el ansia de poder desmedido. Esta forma de comprender al hombre es una torpeza y una inhabilitación muy grave. Como lo diría Leonardo Polo:

[e]l reduccionismo [...] es inadecuado para la situación actual y para el hombre mismo, que es de entrada, lo ha sido siempre, una entidad sumamente compleja. Los reduccionismos terminan en simplificaciones prácticas [...] El reduccionista se condena a embarcar su vida, a entregarla a una vía, a un conducto, a una capacidad de desarrollo. Con ella se ha de identificar, o como

\footnotetext{
Ibídem.

Thomas Hoвbes, Del ciudadano y Leviathan..., pp. 209-210.

Leonardo Polo, Presente y futuro del hombre..., p. 99.
}

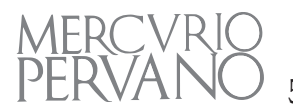


hoy se suele decir, asumir, embarcarse. Como si el hombre fuera un inspector que pregunta: ¿cuál es mi fuerza?, ¿cuál es el tren o el avión que hay dentro de mí? Y, en cuanto averigua el vehículo que lleva dentro, se embarca en él, y así viaja por la existencia. ${ }^{21}$

El reduccionista debe ser expulsado de todo pensamiento, en virtud de que daña la visión del hombre, que es compleja y abierta al mundo. El rechazo a Hobbes es claro, sin embargo no podemos dejar de lado que fue él quien inició la estructura de toda una escuela de pensamiento, que tiene la influencia del nominalismo y del voluntarismo, origen del miedo y del pesimismo antropológico actual. Así, "Hobbes sigue siendo actual; hoy día muchos hombres viven aterrados ante lo incontrolable que es lo más vulnerante. Hobbes se sintió siempre sobrecogido por la presencia del terror en su alma, asustado ante todo y siempre. Pero lógicamente quien percibe en el hombre una voluntad agresiva sin freno, si él no es el lobo mayor de todos -Hobbes no lo era-, solo puede temer (...) El aspecto hostil de la vida se extiende hasta el miedo cósmico. El hombre se encuentra perdido en el mundo (...) El único refugio es el Leviathan, Dios suscitado por la entrega de nuestra propia sustancia dinámica". ${ }^{22}$

Hobbes, entonces, aporta ideas centrales a la mentalidad actual y sigue participando en la configuración de la denominada crisis de la modernidad. Así, en el pensamiento de Hobbes encontramos pesimismo, materialismo, voluntarismo e individualismo. Si hacemos un reflejo en el hombre actual, no hay duda de que encontramos estos parámetros en él, como parte de su crisis y como parte de su entorno. Hobbes postula una humanidad autosuficiente, que se centra en el ejercicio de poder pleno, y donde su existencia se basa en la autoconservación. Ahora la postura que nos da Leonardo Polo al analizar la actualidad de este filósofo es que él mismo peca de reduccionista, ya que concibe la existencia humana solo como una existencia política sustentada en la construcción del concepto y necesidad del Estado, lo que envuelve al hombre en el terror y el miedo.

Así, para Hobbes toda la conducta humana se explica por el miedo, es decir, por la imaginación que anticipa el peligro. El hombre, desde la concepción de Hobbes, vive dominado por el miedo. Es el "único ser vivo en el cual el miedo es crónico: él lo desencadena y lo experimenta". ${ }^{23}$ Conforme lo señala Vargas, el filósofo inglés está embebido de una sobrecarga histórica y emocional:

Con un miedo cósmico, para él la vida era hostil, pues percibía en el hombre una voluntad agresiva y sin freno: él no era el mayor lobo y, por lo tanto, solo podía temer. Así quedaba perdido en el mundo, y este le producía espanto, de tal modo que su único refugio fue el Leviathan, un dios suscitado por la entrega de nuestra propia sustancia dinámica. El gran miedo del

\footnotetext{
Leonardo Polo, Presente y futuro del hombre... pp. 100-101.

2 Leonardo Polo, Presente y futuro del hombre.... p. 56.

23 Leonardo Polo, Quién es el hombre. Madrid, Rialp, 1991, p. 212.
}

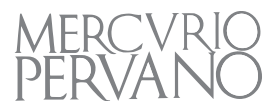


hombre y de la humanidad es la soledad. Si no hay nadie más que nosotros, no nos queda más que empequeñecernos, escondernos en el cosmos, y esto no es posible sin la violencia. ${ }^{24}$

Desde Hobbes el hombre anticipa el futuro y no puede evitar el miedo, y desde esta anticipación aparece la amenaza. El homo homini lupus se evidencia, por lo que es necesario reclamar la construcción del Estado, el cual salvará a la sociedad, atacada por la enemistad universal. De ahí que el Leviathan pensado por Hobbes sea la más pura ficción; la vuelta al mito es clara. Desde esta línea, el pensamiento de Hobbes se encuentra también en los totalitarismos modernos, en especial en el nacionalsocialismo y el marxismo. En su esencia - señala Garay-, tanto el nacionalsocialismo como el marxismo "aparecen como expresiones de esos postulados, [de los postulados hobbesianos] puestos al servicio de una ideología concreta, pretendidamente salvadora y germinadora de una nueva sociedad". ${ }^{25}$ Para esto la libertad aparece en ese momento germinal de la política moderna como una aspiración contradicha por el incremento del poder del Estado; a pesar de que la era de las declaraciones de derechos caracterizadas por el liberalismo propugnaban la autonomía individual y colectiva en la sociedad, la concentración de los poderes del Estado sobre ellas (aparato burocrático) era algo característico en el hombre moderno. ${ }^{26}$

Podemos afirmar entonces que, si bien es cierto que Hobbes no influyó directamente en ningún totalitarismo, le atañe un protagonismo intelectual ineludible en el momento de examinar su genealogía. A su vez, el miedo que irradia Hobbes se aprecia en la sociedad actual en crisis. En vista de que hoy se pone en entredicho la preeminencia del poder estatal ante la falta de capacidad de gestionar los servicios públicos, por ejemplo, ello nos deja en la perplejidad, ante el futuro político y la organización social. No olvidemos que para Hobbes el miedo es el origen del Estado y de todas las relaciones sociales. El pensamiento de Hobbes nos lleva a una sociedad totalitaria (y esto no es hablar de anacronismo), y en razón de que al reducir al hombre a su existencia política se pierde el sentido de la persona.

Pensar en Hobbes es concebir una sociedad en constante conflicto, y donde la convivencia entre los hombres se torna problemática, su frase homo homini lupus calza fácilmente en sociedades que no encuentran alternativas positivas para su desarrollo libre:

24 Alberto VArgas, Genealogía del miedo, estudio desde L. Polo..., p. 109. Vargas con referencia al contexto histórico del nacimiento de Hobbes cita sus apuntes: Vita Thomae Hobbes Carmine Expressa: "estando de pronto en los mares del puerto las naves del enemigo español [la Armada Invencible], con tal miedo concibió [mi madre] de forma prematura que nos parió a mí y al miedo juntamente".

25 Cristián Garay Vera, "La inseguridad y el estado de naturaleza: dos casos, Hobbes y Schmitt". Revista de Derecho Público, 50, 1991, p. 52.

26 Cristián Garay Vera “La inseguridad y el estado de naturaleza... p. 52.

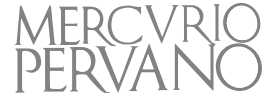


Ver al hombre en una situación tan problemática solo le permite a Hobbes tener una aspiración bastante recortada: neutralizar el conflicto y alcanzar la paz. También hoy este pensamiento está en boga; los grandes proyectos de crecimiento del hombre se han dejado de lado, y basta solo con una mera armonía; tal es el caso de la postura contemporánea del 'crecimiento cero'. La sociedad como una conflictividad constitutiva solo puede tener un remedio extrasocial, que es el Estado: la aspiración central de Hobbes es la paz, o sea, la neutralización del conflicto que expresan frases 'homo homini lupus' y 'bellum omniun contra omnes'. ${ }^{27}$

Así, Hobbes a pesar de pertenecer a una época de mucho tiempo atrás, continúa siendo uno de los filósofos que mejor explica la estructura social del miedo, el cual se constituye en un instrumento para generar en el hombre la necesidad del Estado moderno, el cual es consecuencia de un contrato humano, producto del acuerdo de los hombres. ${ }^{28}$

\section{Apreciación final}

La justificación dela necesidad del Estado en la Edad Moderna tuvo muchas posturas, entre las que se encuentra el pensamiento de Thomas Hobbes, quien, contrariamente a sus contemporáneos, propuso que el hombre en un estado de naturaleza se encontraba en continua guerra de todos contra todos, que él era un homo homini lupus, en que el egoísmo y el miedo eran parte de su existencia. Así, la razón y el deseo de preservación lo impulsan a constituirse a través de un pacto en un estado social, donde el Estado o Leviathan era el único capaz de cumplir con la razón de su existencia, que es únicamente política. Hobbes propone entonces, dentro de su materialismo, un hombre aterrado en un estado presocial, el cual basa su subsistencia en un único fin: la seguridad que le pueda brindar el Leviathan.

El pensamiento pesimista de Hobbes es actual, tan igual como su reduccionismo. La persona y la sociedad, ambas abiertas y libres, se encuentran en crisis, y esto porque las alternativas que escogen son meras aspiraciones, incapaces de crear en la persona y la sociedad un crecimiento o perfeccionamiento positivo. En este sentido, la sociedad conflictiva busca al Estado como un remedio al margen de la tendencia social del hombre, para lograr la paz. Igualmente el "motor del contrato social hobbesiano se encuentra en la pasión [...]: el miedo. Para Hobbes es precisamente el miedo el origen del Estado y de todas las relaciones sociales y, sobre todo, es lo que lleva al hombre a abandonar su estado natural, para rescatar la seguridad perdida que antes solo había otorgado la fe en Dios". ${ }^{29} \mathrm{Si}$ hoy buscamos la existencia de un Estado paternalista, y buscamos

\footnotetext{
Alberto VArgas, Genealogía del miedo, estudio desde L. Polo... pp. 111-110

28 Cfr. Leonardo Polo, Persona y libertad. Navarra, Eunsa, 2007, p. 183.

29 Alberto VArGas, Genealogía del miedo..., p. 110.
}

60

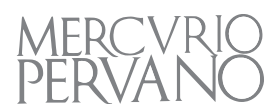


la solución a los problemas sociales en él, estamos mirando al aparato estatal como Hobbes. La sociedad actualmente se ha olvidado del consenso alejado del miedo, y de la tensión de la guerra y del conflicto que aparecen día a día. El miedo y la mentira gobiernan el mundo, así como la indiferencia ¿herencia de Hobbes? No hay duda de que Hobbes es actual y necesitamos contrarrestarlo. Por tanto, tan igual como Leonardo Polo señala: "el reduccionismo debe ser desechado en todos los órdenes: en el plano histórico, en el plano científico y el plano de la autointerpretación".

En este sentido, en Hobbes el hombre es un miedoso e inseguro, un hijo que soluciona su problema de paz con el padre: el Estado. Hobbes no estudia al hombre en todas sus facetas, sino solo en una de ellas, justamente en su tendencia al egoísmo y a la destrucción. Su pensamiento psicológico hunde al hombre en una crisis incapaz de salir por sí mismo. Así, el hombre de la crisis de la modernidad es uno angustiado y desesperante frente a una sociedad totalitaria, donde el ser persona no cuenta para alcanzar la paz deseada en un Estado. 


\section{Bibliografía}

Garay Vera, Cristián, "La inseguridad y el estado de naturaleza: dos casos, Hobbes y Schmitt". Revista de Derecho Público de la Universidad de Chile, 50, 1991, pp. 51-72.

Hobbes, Thomas, Del ciudadano y Leviathan. Madrid, Tecnos, 2013.

Meinecke, Friedich, La idea de la razón de Estado en la Edad Moderna. Madrid, Centro de Estudios Políticos y Constitucionales, 1997.

Polo, Leonardo, Presente y futuro del hombre. Madrid, Rialp, 2012.

Polo, Leonardo, Quién es el hombre. Madrid, Rialp, 1991.

Polo, Leonardo, Persona y libertad. Pamplona, Eunsa, 2007.

Vargas, Alberto, Genealogía del miedo, estudio desde L. Polo. Cuadernos de Pensamiento Español n. ${ }^{\circ}$ 69, Pamplona, Universidad de Navarra, 2017. 